\title{
Legado de la comisión corográfica en un país de regiones $^{1}$
}

Legacy of the geographic commission in a country of regions

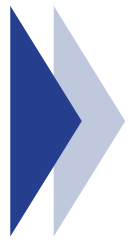

\section{Patricia Ilse Ricardo Calzadilla}

Docente Área de Humanidades. Facultad de Ciencias y Tecnologías. Vicerrectoría de Universidad Abierta y a Distancia de la Universidad Santo Tomás. Licenciada en Derecho, Universidad de La Habana y Magíster en Filosofía Latinoamericana, Universidad Santo Tomás.

E-mail:patriciaricardo@ustadistancia.edu.co

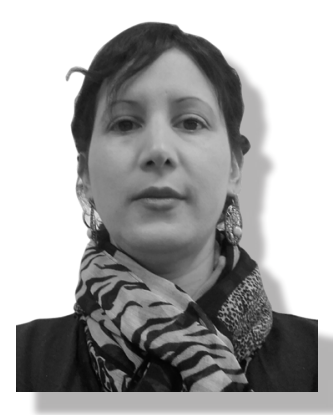

1. Artículo del contenido presentado en la ponencia al X Congreso Virtual de la Facultad de Ciencias y Tecnologías. 


\section{RESUMEN}

Para un sector de la ciudadanía, la perspectiva de las regiones como entes políticoadministrativos, constituye un horizonte que posibilita la solución de apremiantes problemas nacionales. El manejo de espacios geográficos y sus recursos humanos, ha sido y seguirá siendo un tema de interés para la política pública en el país. Esta herencia tiene como cimiento las tesis del federalismo, defendidas desde los inicios de la República, y que tienen un momento cumbre en las reformas de Medio Siglo (XIX), las cuales fueron diversas y lograron, en la práctica, transformaciones que habían sido anheladas por los defensores del liberalismo.

Para llevar a vías de hecho las transiciones que se querían, era necesario conocer más sobre el territorio nacional y así establecer las decisiones políticas más oportunas. Es por ello que a partir de 1850 la Comisión Corográfica comienza su actividad y con ello la exploración del país buscando hacer más patente la composición de las regiones que conformaban la nación. Este empeño representa un momento significativo de la historia de Colombia desde la perspectiva del federalismo que buscó legitimar la diversidad como rasgo distintivo de la nación.

Palabras Clave: Comisión Corográfica, regiones, división política - administrativa.

\section{AbSTRACT}

For some of the citizens, the perspective that understands the regions as politicaladministrative entities represents a future which makes possible to solve the most urgent national problems. The management of the geographical places, as well as its human resources, has been and will still be a national public politics concern. This heritance has a solid foundation on the theories of federalism unheld from the beginning of the Republic, which crowning moment was marked by the XIX mid-century reforms. These political changes were varied and got practical transformations which had been wished by the liberalism defenders for so long.

To make the desirable changes happen, it was necessary to get a better knowledge of the national territory and, thus, make the most accurate political decisions. For this reason, from 1950 the Chorographic Commission begings its activity and, with it, the country exploration in order to make more evident the way in which the national regions were composed. Such efforts represent a significant moment in Colombia's history, from the federalism perspective, which seeked to legitimise diversity as a national dinstinctive feature.

Keywords: Choreography commission, regions, politic - administrative division.

\section{Introducción}

La realidad patente de Colombia: su naturaleza, cultural, historia, ha determinado que sea asumida como un país de regiones. Contexto que ha sido un desafío en los procesos de construcción de la identidad nacional. Muchas han sido las situaciones, durante la historia de la nación, que han girado en torno al tema de las características singulares de la realidad colombiana. La Constitución Política de 1991reconoce este escenario y rescata a la región como escenario de la división política administrativa del país. Así se consigna en la Carta Magna: 
Titulo XI de la organización territorial

Artículo 286. Son entidades territoriales los departamentos, los distritos, los municipios y los territorios indígenas. La ley podrá darles el carácter de entidades territoriales a las regiones y provincias que se constituyan en los términos de la Constitución y de la ley.

Artículo306. Doso más departamentos podrán constituirse en regiones administrativas y de planificación, con personería jurídica, autonomía y patrimonio propio. Su objeto principal será el desarrollo económico y social del respectivo territorio. (Const., 1991, art. $286,306)$ Esto muestra las perspectivas de regiones administrativas y de planificación, como entes territoriales y no solo reconociéndolas como regiones naturales. Un momento significativo, en este sentido, lo constituyó la Asamblea Constituyente, donde un sector de sus participantes defendió la posición de corte federalista, buscando así el reconocimiento de un país plural con amplias posibilidades económicas y sociales por las características de su naturaleza y cultura. Esa posición respaldaba la relación entre la realidad del contexto nacional y las posibilidades de desarrollo que la misma posibilitaría.

También el enfoque federalista fue una reacción a la propuesta de la Constitución de 1886, que en los más de cien años de vigencia presentó posiciones contrastantes en cuanto al modelo político - administrativo del país, pero sin perder su perspectiva centralista.

En relación con el articulado de la Constitución de 1991 que plantea la posibilidad de las regiones como entes territoriales, Orlando Fals Borda (1997) explica en su texto Postulados del Federalismo Regional en Colombia:

La integración geopolítica de este tipo regional I provincial, es un movimiento que conviene en la solución de grandes problemas como son los que nos presenta el manejo de los recursos naturales: ríos, cuencas, selvas, páramos, vías, energía y producción de alimentos (...) Para ello, la región resulta ser una unidad territorial ideal que, al inducir un mejor gobierno en el nivel local, pueda convertirse en un Estado Región. (p.74)

[...]cuando se estudiaron los elementos regionales, con base en el archivo de la Comisión de Ordenamiento Territorial, se descubrió que las regiones legales podían acercarse bastante a las regiones histórico culturales. Este inesperado descubrimiento no pudo explicarse sino como restado de una perspectiva de larga duración [...], que hace de las regiones entes reales en más de un sentido. Porque estas regiones reales han desarrollado, cada una en su territorio, núcleos fuertes de identificación propia, focos donde se preservan la idiosincrasia de sus habitantes y el sabor de lo raizal. (p.77)

Para un sector de la ciudadanía, la perspectiva de las regiones como entes políticoadministrativos, constituye un horizonte que posibilita la solución de apremiantes problemas nacionales como son: el descuido económico, educativo, la falta del poder público del Estado en zonas apartadas del país; causas que han conllevado a la prolongación de la violencia en el territorio nacional. La fórmula, según esta posición, no se encuentra en crear un andamiaje técnico-jurídico que las justifique; sino en el reconocimiento de un contexto que permita recuperar a las comunidades con mejoras sociales.

Las regiones en Colombia desde la perspectiva de la división política administrativa de un país es un tema sensible y se aborda con prevenciones, por el temor a nuevas restructuraciones de los límites fronterizos, así como la exaltación de los regionalismos que siempre ha estado presente en la historia del país. 
Ejemplos recientes de cómo va tomando forma esta perspectiva se observan en las Corporaciones Autónomas Regionales, que son, según reconoce el artículo 1 del Decreto 1768 de 1994:

\begin{abstract}
"Entes corporativos de carácter público, creados por la ley, integrados por las entidades territoriales que por sus características constituyen geográficamente un mismo ecosistema o conforman una unidad geopolítica, biogeográfica o hidrogeográfica, dotados de autonomía administrativa y financiera, patrimonio propio y personería jurídica, encargados por la ley de administrar, dentro del área de su jurisdicción, el medio ambiente y los recursos naturales renovables y propender por su desarrollo sostenible, de conformidad con las disposiciones legales y las políticas del Ministerio del Medio Ambiente."
\end{abstract}

Otra opción que se analiza es la posibilidad de regiones delimitadas por sus recursos hídricos, una cobertura que responda más a la naturaleza de las principales cuencas hidrográficas. Ernesto Guhl Nannetti (2016), miembro de la Academia Colombiana de Ciencias Exactas, Físicas y Naturales, explica la situación que se está dando con la riqueza hídrica de Colombia:

... esta abundancia está amenazada. La creciente contaminación por la falta de tratamiento de las aguas residuales urbanas y actividades como la minería ilegal y legal y la agroindustria afectan la salud pública y los ríos no pueden utilizarse en la práctica. Asimismo, el cambio climático acentúa los extremos entre lluvia y sequía y amenaza el futuro de los páramos $[\ldots]$

La disponibilidad de este elemento podría convertirse en un poderoso instrumento para ordenar el territorio y definir los usos de los suelos.

La puesta en marcha de esta posibilidad depende de crear el marco jurídico adecuado, que como lo ordena el fallo debe presentar el Ministerio de Ambiente y Desarrollo Sostenible al Congreso como un proyecto de ley...(p. 6).

El manejo de espacios geográficos y sus recursos humanos, ha sido y seguirá siendo un tema de política pública en el país. Esta herencia tiene como cimiento las tesis del federalismo defendidas desdelos inicios de la República. En relación con ello, la Comisión Corográfica del siglo XIX representa un momento significativo de la historia de Colombia desde la perspectiva del federalismo que buscó legitimar la diversidad como rasgo distintivo de la nación. Los resultados que se proponía respondían a los intereses de un sector de la sociedad que deseaba legitimar y afianzar su poder local, teniendo como argumento las distinciones que ofrece a un contexto sus características naturales, culturales e históricas. Conocer este pasado permite una profunda compresión de la construcción de la identidad nacional entendida desde la más raigal conexión con su historia local, regional y nacional.

Estehechohistóricoseenmarca en elproceso de nacimiento, e inicio, de la construcción de las jóvenes repúblicas de América. La historia de Hispanoamérica experimentó una transición desde todos los ámbitos después de lograda la Independencia. En ese contexto, los nacientes países necesitaban construir realidades diferentes al pasado. La política, la educación no fueron ajenas a las transformaciones y entre las nuevas alternativas que se aprecian en el período podemos señalar: el interés por reconocimiento del territorio nacional, las modificaciones en los contenidos y las formas de trasmisión del saber.

En relación con ello, los gobiernos de turno y las élites intelectuales de la recién independizada Nueva Granada, buscaban y se enfrentaban por definir cuál sería el sistema político más conveniente para el país: Centralismo o Federalismo. Disputa 
que se remonta a los albores de la Guerra de Independencia contra el poderío colonial español. Para 1848, nacen los partidos políticos tradicionales Liberal y Conservador, y en 1849 llega a la Presidencia de la Nueva Granada el liberal José Hilario López y con él se profundizan las reformas liberales de mitad de siglo, las que buscaban nuevas perspectivas y fundamentos de la nacionalidad desde el Federalismo.

Las reformas de MedioSiglo, fueron diversas y lograron en la práctica transformaciones que habían sido anheladas por los defensores del liberalismo desde muchas décadas atrás: eliminar o dividir los resguardos indígenas, suprimir los diezmos, desamortizar los bienes de manos muertas, eliminar los estancos, que los impuestos aduaneros fueran destinados a las rentas del Estado, abolir la esclavitud y liberar el comercio. El cambio de mentalidad, la transformación ideológica también formaba parte de las estrategias que llevarían a nuevos horizontes en la joven República y que debían complementar las transformaciones políticas y económicas que se iban logrando.

Para llevar a vías de hecho las transiciones que se querían, era necesario saber, y así establecer las decisiones políticas más oportunas. Ya desde 1839, el Congreso de la República había aprobado una ley que reconocía la necesidad de explorar el territorio nacional y que permitiera un estudio de los recursos con los que contaba el país. Esta ley constituyó fundamento de la Comisión Corográfica que comenzaría su actividad a partir de 1850.

Es necesario tener en cuenta que la Comisión Corográfica tuvo como antecedente el artículo Estado de la geografía del Virreinato de Santafé de Bogotá, con relación a la economía y al comercio, publicado por Francisco José de Caldas en el Seminario del Nuevo Reino de Granada.
El profesor Efraín Sánchez (1999) en el libro Gobierno y geografía. Agustín Codazzi y la Comisión Corográfica de la Nueva Granada, explica que Caldas da un concepto de geografía como base fundamental de toda reflexión política. Sánchez reconoce que:

Caldas miraba hacia el futuro con patriótica esperanza. Con extraordinaria visión imaginó un proyecto que cuatro décadas más tarde se iría a materializar en la Comisión Corográfica. Así escribe Caldas: "Si se formase una expedición geográfica - económica destinada a recorrer el Virreinato; si ésta se compusiese de un astrónomo, de un botánico, de un mineralogista, de un encargado de la parte zoológica y de un economista, con dos o más diseñadores... no hay duda que dentro de pocos años tendríamos la gloria de poseer una obra maestra en la geografía y en la política, y de haber puesto los fundamentos de nuestra

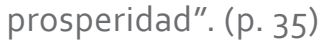

Fueron muchos los aspectos a los que se comprometieron los comisionados como parte de las labores de la Comisión Corográfica: desde la exploración del contexto nativo (accidentes geográficos, recursos naturales, clima) y de las realidades sociales y políticas del país (costumbres, historia, actividades económicas, características del habla, composiciones sociales). Agustín Codazzi, constantemente destacaba entre sus objetivos fundamentales el de "dar a conocer estas ignoradas regiones".

Según Restrepo, Arboleda \& Bejarano (1993) en su texto Historia Social de la Ciencia en Colombia:

Para el liberal romántico, la identidad nacional no se fundaba en la tradición española ni en la religión católica, sino en lo típico de la provincia, en las costumbres del aldeano y en el paisaje, como se percibían desde el centro. Así, el carácter nacional no se definía por lo más general, común con lo español, sino por lo específico, por el detalle de la región. (p. 160) 
En el texto Un imaginario de la Nación. Lectura de láminas y descripciones de la Comisión Corográfica, la profesora investigadora de la Universidad Nacional, Olga Restrepo (1999) explica cuáles son los elementos que intervienen en la construcción de ese imaginario de la nación que será compartido por un amplio sector de las élites durante todo el período de la Revolución de Medio Siglo y del período del Radicalismo y que son asumidos en la obra en la Comisión respondiendo a los intereses Federalista. En este sentido plantea:

\section{Representación emocionada del paisaje}

El primer elemento de esa construcción que elaboran los comisionados se encuentra en la representación emocionada del paisaje, dibujado con el propósito de generar una identidad con el suelo de las comarcas que visitan $[\ldots]$

Ellos procuran a la vez generar los sentimientos de compenetración con el paisaje que es objeto de admiración y exaltación estética. País y paisaje que exigen un comportamiento ético de sus habitantes [...]

Y en esta descripción sobresalen la variedad de climas, la exuberancia de su flora y fauna y, también la índole diversa de sus pobladores [...] (p.41)

2.El pasado constituye otro elemento importante en la construcción de la identidad nacional que realiza la Comisión Corográfica. Pero pasado como nostalgia, como pérdida, como componente negado en una identidad cercenada [...] (p. 44)

3. [...] se crea también esa diversidad, que se convierte en un rasgo objetivo de la nación y que, como hecho descubierto, "demanda" cierto tipo de organización social [...] no se define nada claramente homogéneo en los habitantes de la Nueva Granada en cuanto respecta a su común origen étnico o marcador racial o social, y mucho menos en las costumbres, los modos de vida o las tradiciones. Lejos de inventarse una unidad nacional basada en el común origen étnico, o en las tradiciones, las creencias o la lengua compartida, La Comisión se esfuerza por destacar la diversidad como un elemento importante que va a permitir identificaciones segmentadas [...] (p.53)

4. Ciudadanía como criterio y fin último de la unificación nacional

[...] mientras que para Ancízar, la efectiva ampliación de las condiciones de participación de la ciudadanía política y social traería como consecuencia la mayor homogeneidad de los ciudadanos, Pérez concibe la ilustración de los habitantes como una precondición para su inclusión posterior como ciudadano[...]. (p.56).

La Comisión Corográfica tenía como meta redescubrir el país. Para ello era necesario utilizar técnicas de investigación que les permitiera obtener un conocimiento fehaciente de la realidad. Los comisionados eran hombres imbuidos del espíritu positivista del momento. El equipo estuvo formado por personas que mostraron habilidades en el dibujo, la cartografía, la escritura y la botánica. Todo este saber se pondría en función de guiar el norte a los nuevos rumbos de la política. Para cumplir los objetivos, la Comisión conformó un equipo de investigadores con roles específicos.

Como líder de la Comisión estuvo el ingeniero Agustín Codazzi, geógrafo italiano, quien ya había realizado el mapa de la naciente República de Venezuela. Su tenacidad determinó el impulso y los logros alcanzados por la Comisión. Fueron múltiples los obstáculos que tuvo que enfrentar junto a su equipo: falta de recursos económicos, adversidades climáticas, desinterés por parte de algunos gobernantes en relación a esta empresa. Pero sus esfuerzos dieron fruto: los 
resultados geográficos y del estudio social realizado por la Comisión han sido tenidos en cuenta hasta la actualidad, ello ha determinado que esta iniciativa ocupe un lugar significativo en la historia nacional.

Codazzi publicó la Geografía física y política de las provincias de la Nueva Granada; así como otros textos que daban cuenta de las actividades y resultados logrados. Murió en la etapa de mayor vorágine de la Comisión. Los ingenieros Indalecio Liévano, Manuel Ponce, y el dibujante Manuel María Paz fueron los siguientes líderes de la Comisión. Con ello, la información obtenida se materializaría en la obra cartográfica: el Atlas de los Estados Unidos de Colombia (1864) y el Atlas geográfico e histórico de la República de Colombia (1889).

El primer cronista de la Comisión fue Manuel Ancízar: político, literato, intelectual reconocido en la Nueva Granada cuando se incorpora a la Expedición. Desde las primeras descripciones, hacer sentir el espíritu romántico de la época, exaltando los acontecimientos, situaciones que iban experimentando los comisionados. Los textos elaborados por este neogranadino fueron publicados en periódicos y posteriormente compilados en un libro titulado Peregrinación de Alpha por las provincias del norte de la Nueva Granada, fue uno de los primeros éxitos editoriales en la historia de Colombia, pues a pesar del alto grado de analfabetismo del momento, muchos connacionales se acercaron a los textos con el interés de conocer qué había más allá de los perímetros de la ciudad o de los pueblos donde vivían. Santiago Pérez, otro reconocido político e intelectual de la época, sustituyó a Ancízar en la Comisión y escribió una obra que dio continuidad al registro de los eventos que tenían lugar durante los viajes de la Comisión. El título del nuevo libro fue: Apuntes de Viaje.

De la botánica, se encargó José Jerónimo Triana. Formó parte de la Comisión hasta 1856 y después realizó el trabajo de gabinete $\mathrm{e}$ investigativo en Europa. Los logros alcanzados fueron reconocidos por la comunidad científica europea y los resultados contribuyeron a divulgar la grandiosidad de la flora colombiana.

Las ilustraciones elaboradas durante la Comisión son el resultado de la labor de varios pintores: Carmelo Fernández (venezolano), Enrique Price (inglés) y Manuel María Paz (neogranadino). Todos desearon mostrar los detalles que permitían reconocer una nación variada, para ello se enfocaron en resaltar delas regiones sus actividades económicas, paisajes, tipos humanos, tradiciones, instrumentos de trabajo, condiciones de los caminos, nivel de desarrollo regional, la historia. Muy importante fue el resultado cartográfico, pues los mapas levantados permitieron tener una idea de la extensión y geografía del territorio nacional. Todo ello contribuyó a crear las bases de la conformación de la identidad nacional.

El país se vio abocado a guerras civiles durante los años que se realizaron los viajes de la Comisión. Las divergencias entre los conservadores y los liberales no se limitaban al terreno de la argumentación política. Nuevamente las guerras civiles sería la situación constante para imponer uno u otro punto de vista. Es por ello que en este contexto se dio cambio de las Constituciones políticas y de la división política administrativa del país. Al tiempo, también cambiaron los nombres de la nación: República de la Nueva Granada, Confederación Granadina, Estados Unidos de Colombia y República de Colombia. Esta realidad incidía en los resultados de los trabajos cartográficos realizados por la Comisión.

Vale la pena señalar que, hasta la actualidad, la Comisión Corográfica no es un hecho histórico reconocido con tanta amplitud como lo fue la Expedición Botánica. Esta última ha sido más reconocida teniendo en 
cuenta diversos factores: el origen borbónico de la misma, la figura de Mutis y su vínculo con la Ilustración europea, y la relación de sus participantes con la Guerra de Independencia.

Sin embargo, es necesario resarcir el olvido reivindicando los logros de la Comisión Corográfica del siglo XIX. Con ella la profesión del ingeniero, del cartógrafo, la labor de los dibujantes va tomando más importancia., teniendo en cuenta la aspiración al progreso inmediato por parte de las jóvenes Repúblicas latinoamericanas. La Comisión muestra como el conocimiento no se limita al espacio de las aulas universitarias, el saber también guardaba una estrecha relación con lo empírico, con el contexto, con la realidad sensible que es necesaria registrar y analizar. Los resultados no se asumían por la élite intelectual del país como una verdad de Perogrullo, eran cuestionados y determinaban un ambiente de interrogante ante la ciencia, lo cual también catalizó ese interés por el estudio.

Como ejemplos puntuales del legado aportado por la Comisión, podemos señalar el descubrimiento de nuevas especies de plantas halladas por José Gerónimo Triana, aporte mayor que el realizado por la mismísima Expedición Botánica y las contribuciones realizadas por Manuel Ancízar en el campo de la naciente Sociología.

Desde otra perspectiva, podríamos valorar como los trabajos gráficos y literarios elaborados por los comisionados, además de mostrar la diversidad del país también tenían una intencionalidad ideológica: la identidad construida por el otro desde una actitud de exclusión. Las descripciones de los textos y las láminas, además de la variedad, muestran una segmentación de tipos raciales que exaltan la raza blanca y menosprecian lo negro, lo indio y lo mestizo. Todo ello, inspirado en el positivismo con su carga de evolucionismo social, pretendiendo vender como modelo idóneo una estética más cercana con lo europeo y así eliminar la "condición de inferioridad y ascender a la altura de naciones modernas". Esta mirada no es ajena a circunstancias de la realidad actual del país, lo que muestra cómo se repiten patrones y mecanismos en la construcción de la identidad nacional.

Múltiples pueden ser las interpretaciones que se realicen de la obra proporcionada por la Comisión Corográfica. Lo que es común a cualquier reflexión es la diversidad que hace patente esta empresa en todas las dimensiones que conforman la morfología y la cultura del país. Este legado invita a recorrer viejos caminos y repensar a la región como una opción para el ordenamiento territorial, la cual puede tener más a la mano el conocimiento de los problemas y, por tanto, una mejor solución a los mismos.

\section{REFERENCIAS}

Congreso de la República de Colombia) (1991). Constitución Política de Colombia [Const.] Artículo 286, 302 [Título XI]. Recuperado de: http://www.secretariasenado.gov. co/senado/basedoc/constitucion_politica_1991.html

Fals Borda, O. (1997). Postulados del Federalismo Regional en Colombia. En O. Fals Borda, L. Parejo, J. Rodríguez (Eds.), El Federalismo en Colombia. Pasado y perspectivas (faltan páginas). Bogotá: Universidad Externado de Colombia.

Guhl, E. (2016, 17 de septiembre). Región hídrica de Bogotá, oportunidad de gestión sostenible del agua. UN Periódico. No. 203 (Edición Especial), p.6. Recuperado de: http://www.unperiodico.unal.edu. co/dper/article/region-hidrica-de-bogota-oportunidad-de-gestion-sostenible-del-agua.html 
Monal, I. (2007). Ensayos americanos. La Habana: Editorial Ciencias Sociales.

Presidencia de la República. (3 de agosto de 1994). Por el cual se desarrolla parcialmente el literal h) del Artículo 116 en lo relacionado con el establecimiento, organización o reforma de las corporaciones autónomas regionales y de las corporaciones de régimen especial, creadas o transformadas por la Ley 99 de 1993. [Decreto 1768 de 1994]. Recuperado de: http:// www.acnur.org/t3/fileadmin/Documentos/BDL/2008/6526.pdf?view=1

Restrepo, O. (1999). Un imaginario de la Nación. Lectura de láminas y descripciones de la Comisión Corográfica. Anuario Colombiano de Historia Social y de la Cultura, (26), 30-58.

Restrepo, O., Arboleda, L. C. \& Bejarano, J. A. (1993). Historia social de las ciencias. Historia natural y ciencias agropecuarias. Tomo III. Santafé de Bogotá: Tercer Mundo Editores.

Sánchez, E. (1999). Gobierno y geografía. Agustín Codazzi y la Comisión Corográfica de la Nueva Granada. Bogotá: Editorial Banco de la República, El Ancora Editores. 